\title{
LA CIUDAD: ENTRE LA BIOGRAFÍA Y EL OBJETO
}

\author{
Juan Díez del Corral \\ Arquitecto, profesor de la Escuela de Artes y oficios de Logroño. \\ Fue Decano del COA de la Rioja 1996-98
}

\begin{abstract}
El autor propone diversos pensamientos y unas pequeñas y sensatas historias urbanas autobiográficas que permiten aprehender algunos de los cambios radicales en la viva (pero deteriorada) relación de los hombres con las ciudades. Frente al "ciudadano universal», que es ciudadano abstracto de un universo ilocal, se nos invita a repensar y recuperar la condición de vecino y la calidad de buena vecindad, que es la que debe fundar la verdadera ciudadanía y los hábitos de la democracia y la justicia.
\end{abstract}

L a ciudad es indefinible», nos decía el profesor de urbanística -uno de los profesores más prestigiosos de la Escuela de Arquitectura de Barcelona en los años setenta. La asignatura que debía enseñarnos qué era una ciudad, empezaba por negarla, o por desdibujarla: la ciudad es algo muy complejo, o muy abstracto, urdimbre de intereses, cruce de caminos, depósito de historias, mercado imperfecto, escenario de la lucha de clases, y así sucesivamente. Todo, menos definible. Acaso, como los hombres, como el hombre mismo considerado en abstracto. Así que el estudio de las ciudades se convertía siempre en disecciones anatómicas de uno u otro órgano, el estudio detenido de una u otra función. En aquella época en que la cultura miraba a las cosas desde la influencia de la pintura abstracta, el teatro abstracto, la poesía abstracta o las ideologías abstractas, al poner nuestra mirada sobre la ciudad no podíamos ver sino líneas inconexas, manchas de colores, trozos de materia o fragmentos de textos.

No definir la ciudad es la mejor manera de que la ciudad se vuelva indefinida. En aquella época, las ciudades se indefinían, se construían las unas muy parecidas a las otras, y se expandían indefinidamente absorbiendo otros pueblos y otras ciudades hasta el punto de no saber muy bien ya dónde estaba uno: esta acera es de Barcelona y la de enfrente es de Hospitalet decían, como quien cuenta un chiste, los vecinos de algunas de sus calles.

Era un chiste, un mal chiste, desde luego. Pero, bien pensado, no tanto el que contaban los vecinos como el que enseñaba en clase el profesor de urbanística. La mirada abstracta, analítica, racionalista, antropológica, sinté- 
tica, ideológica o tecnológica, era siempre una mirada grotesca, una mirada de chiste. Tardamos mucho en darnos cuenta. Muchos siguen instalados en esa mirada. Aquel profesor de urbanística edifica ahora como un poseso y hasta gana premios de diseño ADI FAD por la construcción de viviendas en masa.

Con lo fácil que es decir que la ciudad es un lugar, un lugar concreto: Barcelona, entre el Ter y el Llobregat a orillas del Mediterráneo; Madrid, al sur del Guadarrama, junto al río Manzanares; Logroño, pegado al Ebro, entre el monte Corvo, el monte La Pila y el monte Cantabria. Con lo fácil que es decir que cada ciudad tiene un nombre propio, inconfundible y definitorio. $Y$ que ese nombre pasa a los habitantes de la ciudad, de manera que los de Barcelona son barceloneses, los de Madrid, madrileños y los de Logroño, logroñeses.

Pero no seamos incautos con las definiciones sencillas porque la abstracción siempre está al acecho. Como consecuencia de que unos habitantes vivan en ciudades, hemos aprendido a decir que todos poseen el nombre de ciudadanos, así en abstracto. $Y$ vuelve el error, vuelve el chiste grotesco. Los ciudadanos del mundo, de que tanto se habla, no existen, porque el mundo no es una ciudad. Hay ciudadanos de Barcelona, ciudadanos de Madrid y ciudadanos de Logroño, y ese estatus es diferente en cada caso, porque cada ciudad es siempre distinta.

Las ciudades son lugares concretos con nombres propios donde viven unos hombres, que por el hecho de vivir en ellas reciben el nombre de ciudadanos de esas ciudades en con- creto. Este es el saber que se ha perdido con las abstracciones de este siglo... y con las enseñanzas de los profesores de urbanística.

En el simposio de Nápoles de noviembre de 1999 para el que puse en orden estos pensamientos, su organizador Eduardo Mira (un estupendo erudito de ciudades y un sabedor profundo de sus verdades), planteó a los ponentes una pregunta con estas cuatro palabras «El pasado urbano vivo».

A tenor de mi experiencia discente, mi respuesta fue claramente afirmativa. En la relación de los hombres con las ciudades hubo un pasado distinto del presente, un tiempo en que los hombres eran de unas ciudades o de otras, y no ciudadanos en abstracto. $Y$ esa relación era una relación dada, no una relación elegida, una relación, podríamos decir, inocente.

Pues bien, los hombres llamamos «vivo» a lo que es inocente, esto es, a estados como la niñez, o como el amor, o como la tragedia, en los que la vida posee una intensidad superior a la normal, una intensidad desbordante e incomprensible, pasados los cuales, caemos a estadios de consciencia o de reminiscencia, (simples consuelos de la pérdida), cuando no a estados de desconcierto, obnubilación y desesperación por el contraste mediante. Desde cualquiera de estas situaciones podemos afirmar que hubo un pasado urbano vivo.

La relación de los hombres con sus ciudades era por lo general, hasta antes de la modernidad, una relación natural, inocente, una relación viva, de la que ambas partes gozaban y se beneficiaban. Y hay datos históricos del 
comienzo del deterioro de esa relación. Un deterioro mutuo, no se vaya a pensar que sólo fue el hombre el que empezó a abandonar su ciudad; también ella empezó a abandonarle a él. En la Historia de la Arquitectura del Renacimiento, Leonardo Benévolo cuenta cómo Corneille, en 1643, impresionado por la rapidez con la que se había construido la Isla de Saint-Louis, escribió estos versos: «Paris semble a més yeux un pays de roman/ J'y croyais çe matin voir une ile enchantée/ Je la laissai deserte et la trouve habitée», y comenta a continuación: «por primera vez registra la poesía la sorpresa que producen estas bruscas transformaciones urbanas; la forma de la ciudad ya no es un fondo inmóvil del acontecer individual, sino un sistema que cambia, en algunas partes con un ritmo similar al de las experiencias humanas».

¿Quién no se ha sentido decepcionado por su propia ciudad cuando, después de un largo viaje o una estancia prolongada fuera de ella, ha regresado allí y se ha encontrado con que han talado los árboles de su acera, le han cambiado la perspectiva que tenía desde su ventana, han construido un horrible edificio donde antes vivía un viejo pariente, han cerrado la panadería donde compraba el pan o el kiosco donde adquiría el periódico?. La velocidad con que se transforman las ciudades no sólo tiene un ritmo similar al de las experiencias humanas -como dice Benévolo-, sino que en muchos casos tiene un ritmo de cambios incluso muy superior.

Con un ser tan cambiante es difícil tener buenas relaciones, ahora que, para dinámico también el propio hombre moderno, que viaja incesantemente, que cambia una ciudad por otra, que se comunica entre ciudades o que transforma las ciudades en lugares de paso, que se inventa las vacaciones para marcharse de su ciudad, y, por si las vacaciones fueran poco, también los fines de semana cada vez más largos, y si no, los puentes incesantes para huir de ella, y así sucesivamente. Un hombre que, dando la espalda a su ciudad, se proclama ciudadano del mundo...

En la relación de los hombres con las ciudades ha habido un cambio radical que se demuestra con sólo analizar un poco algunas frases que aún decimos y que resultan obviamente anticuadas. Por ejemplo, todavía nos hacemos unos a otros la pregunta « $i$ de dónde eres?», recordando acaso (desvelando) que hubo un tiempo en que los hombres eran de algún lugar concreto al que estaban vinculados de por vida. Un lugar que era el del origen de nacimiento (hecho poco relevante) y sobre todo (y eso era lo importante) el lugar o la ciudad en la que uno vivía. Es cierto que cada vez hay menos gente que pueda dar una respuesta rotunda a esa pregunta mencionando una sola ciudad.

Mi caso - perdonen que me proponga como muestra-, puede ser un buen ejemplo. Yo nací en Madrid, pero he vivido largos periodos de mi vida en Bilbao, en Barcelona, en Logroño e incluso en ciudades o pueblos de menor entidad como Santoña. En cada una de estas ciudades he vivido más de cinco años, tiempo suficiente para sentirme íntimamente vinculado a cada una de ellas. ¿Qué debo contestar cuando alguien me pregunta de dónde soy? 
Echamos la vista a otros hombres de biografías muy conocidas e igualmente nos podemos preguntar, ¿de dónde era Beethoven?, ¿no es más lógico decir que a partir de cierto momento de su vida era de Viena y no de Bonn, a donde nunca volvió?; o también Brahms, ¿era de Hamburgo o de Viena?. Háganse la pregunta Vds. mismos y traten de dar una respuesta; es probable que descubran entonces la debilidad de sus relaciones con la ciudad.

A la hora de hacer una breve reseña para los periódicos, para la historia o para los diccionarios, los casos de Beethoven y de Brahms aún son fáciles pues se pone Bonn 1770Viena 1827, o Hamburgo 1833-Viena 1897, pero aún así no está claro cuándo hicieron el cambio de una a otra ciudad, un dato muy importante porque la última fecha es la de la muerte y no la de la llegada de Beethoven o Brahms a Viena.

Yo propongo que para mejorar un poco nuestra forma de comunicarnos, e incluso para mejorar un poco la deteriorada relación de los hombres con las ciudades, en la reseña de todo hombre (no necesariamente fallecido) se haga constar la fecha en la que uno cambia de ciudad, es decir, la fecha en la que aparece o «nace» en una nueva ciudad.

Voy a usarme a mí mismo como ejemplo, perdonen otra vez la personalización: Juan Diez del Corral, Madrid 1953, Santoña 1963, Logroño 1968, Barcelona 1970, Bilbao 1978 , Logroño 1983, y hasta hoy. El dato de la ciudadanía de un hombre es un dato importantísimo, y no sólo para conocer al hombre sino para conocer la ciudad. Un día, paseando en Viena por el Grinzing encontré una placa en una casa que decía que allí había vivido Einstein -nacido en Ulm (Alemania) 1879, y fallecido en Princeton (USA) 1955-, entre 1927 y 1931. El ya inmenso patrimonio humano de la capital austríaca aumentó un poco más para mí con ese dato encontrado casualmente. Y a la puerta de aquella casa pude imaginar (casi ver) entrando y saliendo al gran sabio, bien a comprar el pan o a darse un paseíto. Por aquellas fechas tendría Einstein entre 48 y 52 años.

Pero el deterioro más profundo en la relación viva de los hombres con sus ciudades no se da por la incesante movilidad de uno y de otra. Elizabeth Taylor -les propongo una metáfora- no es la enemiga número uno de la institución del matrimonio por mucho que se case una y otra vez, porque aún con todo, lo cierto es que se va casando una y otra vez. Los enemigos de la institución del matrimonio verdaderamente son los que no se casan. Así mismo con la ciudad.

El hombre vivió su más intensa relación con la ciudad (la del pasado urbano vivo) cuando tenía la vista puesta en la salvación eterna: mientras él se procuraba la salvación adornó cada una de las ciudades en las que vivió con una hermosísima catedral.

Las cosas cambiaron cuando el hombre dejó de creer en la salvación eterna y prefirió la gloria terrenal. Nunca ha estado muy claro desde entonces si las edificaciones que erigían los hombres en las ciudades eran a mayor gloria de la ciudad o a mayor gloria de su autor. 
Ernst Jünger escribió unas hermosas líneas de gran calado urbano sobre los hombres célebres: «Desde siempre el conocimiento que menos me ha seducido, de entre los que uno puede aspirar a tener, es el conocimiento de las celebridades. A lo que parece, cuando nos hacemos un nombre sufrimos una pérdida proporcional de calidad, en concreto, de esa calidad que cabría calificar de 'calidad de vecino'. En la misma medida que los seres humanos se tornan importantes para la masa, en esa misma medida pierden también su valor de prójimos» (Radiaciones, escrito en Laon, 8 de junio de 1940). El hombre que escribe para las masas, que edifica para las masas, es el hombre que construye su propio nombre para la gloria mundana. Ese hombre, dice Jünger, es un mal vecino: tiene la mirada puesta en su más allá y se desentiende de su calle, de su barrio, y de los seres humanos con los que se cruza en la escalera. Sus templos son las editoriales de libros y periódicos, y su gran catedral, la televisión. ¿Qué tiene que ver con su ciudad ese hombre superurbano, ese «ciudadano del mundo", ese artista al que le saludan en la calle como el hombre de la televisión, el hombre virtual? Esos diosecillos, como los poetas de Platón, no tienen sitio en la ciudad: se les queda pequeña, y cuando se pasean por ella, o la destruyen o la virtualizan.

He vuelto a mirar la casa del Grinzing y me he preguntado qué tal vecino sería Einstein. No sé por qué pero siempre he pensado mirando sus retratos que la sonrisa de Einstein no es la vacía sonrisa de quien mira a la televisión (o a la cámara de fotos) sino la más genuina y amable sonrisa de vecino.
Tres historias urbanas autobiográficas.

a) Veinte años después de haber dejado Barcelona, pasé brevemente por su gran estación de Término (ya empezaban a convertirla en museo) camino de Milán. Salí a la puerta en compañía de mis hijas y pasó por el recién construido carril bici un tipo montado en bicicleta. Levantó la mano y me saludó: ¡eh Juan!, ¿qué es de tu vida? Era Josep Juvé Raventós, un compañero de carrera de arquitectura. Pues bien, nunca he sentido mayor emoción urbana, mayor orgullo de barcelonés. Mis hijas, sorprendidas, me dijeron luego: ¡vaya! es verdad que tú eres de Barcelona, como nos decías. Uno es de una ciudad cuando la gente le saluda por la calle.

b) Al poco de llegar a Bilbao tuve, sin embargo una experiencia más amarga. Llevé mi Citroèn $2 \mathrm{CV}$ a arreglar a un taller y el dueño me preguntó que por qué lo llevaba allí, que quién era yo, que a quién conocía. Le miré ofendido, ¿no dice en ese cartel taller?, debí contestarle. Se encogió de hombros y me dio la espalda. Eso no debía ser suficiente. Si quieres que te lo arregle deberás esperar más de dos semanas -dijo. Me irrité, me enfadé, sentí herido mi orgullo de ciudadano universal, pero con el tiempo, llegué a pensar que aquel hombre me estaba exigiendo ser ciudadano de Bilbao para empezar una simple transacción comercial, y me arrepentí de no haber aceptado el plazo de dos semanas de iniciación que me daba para considerarme urbano, para tenerme por un bilbaíno más.

c) A veces el reconocimiento de la ciudadanía viene por las relaciones externas, por la 
correspondencia postal. El caso de Holanda, un país de mucho comercio exterior, es el más sobresaliente: su sistema postal funcionó durante muchos siglos mediante los nombres de los dueños de las casas y no por el racional sistema de los nombres de las calles y sus números. Todavía en Venecia las cartas no van a las calles sino a los barrios, donde los números de las casas no tienen, dado el laberinto de calles, un orden entendible para alguien que no sea el cartero. En mi correspondencia con un hombre célebre un día me equivoqué en el número de su casa y puse calle de tal 423 en vez de 432. La carta me fue devuelta porque su destinatario no vivía en tal número. Gocé con el incidente porque le reté a ese hombre famoso a escribirme una carta sin poner ni siquiera el número de mi casa. El cartero es uno de los grandes constructores de vecindades.

También lo es la policía, y mucho más los desaparecidos serenos pero no voy a contar anécdotas por tratarse de materia reservada.

Es preciso definir los rasgos de la relación entre los hombres y las ciudades, e incluso darles carta de naturaleza: «formalizar una relación", como se dice cuando un chico y una chica «parece que van en serio». Reducir la ciudadanía a darse de alta en el padrón municipal es confundir la vida con la burocracia. Algo execrable.

Uno de los signos que me parecen muy significativos de esa relación es la instalación de una placa con el nombre del ciudadano en la pared o en la puerta de una casa. Todavía se pueden ver en las puertas de las casas viejas y de los pisos de gente mayor los nombres de sus dueños, aunque cada vez menos. Con el invento de los porteros automáticos los nombres fueron llevados a la calle, lo que me pareció mucho mejor: desde el portal de una casa se podía saber quién vivía en cada piso. Pero un avance tan notorio en la relación de ciudadanía no duró mucho y pronto los nombres fueron desapareciendo de los porteros automáticos... «por razones de seguridad», se decía. Nunca lo he entendido: cuando uno oculta su nombre de la calle es que tiene algo que ocultar, y eso sí que crea inseguridad. El único lugar donde ahora se pueden leer escritos los nombres de los ciudadanos es... en el cementerio.

Es también cierto que la adquisición de una ciudadanía debe llevar un tiempo y unas condiciones de relación con la ciudad. La residencia, el lugar de trabajo han de tener una cierta definición y estabilidad para que esa relación de ciudadanía se desarrolle. También los lugares donde uno se divierte y se encuentra con los demás. La frecuentación de un café, el paseo cotidiano por una acera o la estancia en la plaza de la ciudad o del barrio son actividades que incrementan la relación. Pasar el fin de semana en la ciudad, ya no digamos unas vacaciones enteras, serían hoy en día casi actos litúrgicos que le darían a uno directamente la condición de ciudadano. $\mathrm{Si}$ uno se pone a contemplar como se dan estos signos tan sencillos en su ciudad se queda pasmado: la plaza de mi actual ciudad, por ejemplo, antiguo lugar de ligue y de encuentro humano a todos los niveles, está habitada ahora mayormente por los inmigrantes marro- 
quíes, que son los únicos hombres que conservan el sentido de su función.

La presencia en espectáculos de aforo mediano es otra forma de «dejarse ver». Pero nótese cómo estos acontecimientos van en retroceso: el cine, que ha sustituido al teatro, exige la oscuridad de la sala e impide dejarse ver más que a la entrada o la salida (por no hablar ya de las minisalas que merman el aforo hasta el ridículo). Los deportes, por otro lado, prefieren a las masas que a los ciudadanos. Los ciudadanos van al deporte a ser masa y a vociferar, esto es, a dejar de ser ciudadanos. Se diría que tienen una función orgiástica -acaso necesaria individualmente, pero obviamente no urbana. De los bailes modernos mejor no hablar porque son la expresión más cabal del retorno del ciudadano al estado tribal.

Cinco años de residencia y trabajo, conocer a más de cien personas y ser reconocido por ellas, tener el nombre en el portero automático, ser reconocido por el cartero, ser saludado por el dueño de al menos tres bares cuando uno entra, conocer de memoria todos los detalles de un par de paseos serían, por ejemplo, standards básicos para adquirir la ciudadanía.

La intensificación de la relación de ciudadanía ha de modificar por fuerza ciertos hábitos políticos impuestos desde el Estado (enemigo número uno de las ciudades, como me enseñó Eduardo Mira) o desde los medios de comunicación (enemigo número dos, sólo por orden de aparición). Es preciso revisar desde nuestra relación de ciudadanía los hábitos de la democracia, la nobleza o la justicia.
- El voto ha de ser consecuencia de la ciudadanía -siempre entendida desde el cumplimiento de los standards citados y no sólo como empadronamiento burocrático. Los ciudadanos universales pertenecen a otro mundo y no deben tener derecho al voto más que en sus universos ilocales. De hecho ya no votan: son en buena parte los que engrosan ese enorme porcentaje de abstención que cada vez va creciendo más y más en las democracias modernas.

La fuerza del voto local sería tal que incluso podría mantenerse de por vida, porque uno no es sólo lo que es sino lo que ha sido, y lo que pueda ocurrir en ciudades en las que hemos vivido es algo que también nos afecta profundamente.

- La nobleza ciudadana deberá sustituir a la vieja nobleza de sangre, convertida en la actualidad en nobleza de papel couché. El título básico de nobleza es el de ciudadano, pero con mayores méritos, pongamos que vivir veinticinco años seguidos en la ciudad, conocer a mil y ser reconocido por cinco mil personas en ella, haber votado tantas veces en las elecciones municipales, y otras cosas así, podría obtenerse ya una baronía o un marquesado y de ahí para arriba, hasta conde, duque o príncipe de la ciudad. La ventaja de la nobleza urbana frente a la de sangre es que no es hereditaria: se la tiene que ganar uno a pulso. Obviamente los nobles tendrían asientos reservados en los autobuses urbanos o accesos preferentes a conseguir entradas para los teatros y los conciertos. ¡Qué lustre 
darían a las ciudades unos individuos de tal categoría urbana!. Estoy seguro que los turistas, esos seres tan innobles, los mirarían embobados.

- La justicia ha olvidado a las ciudades tiempo ha. El pueblo no. Hace un año, más o menos, leí en la prensa la historia de un asesino que, cumplidos sus años de condena en prisión, volvió a la ciudad asturiana donde había cometido su asesinato. Los hermanos de la víctima se prepararon y a las pocas semanas de su regreso le mataron. En sus declaraciones dijeron: nosotros nunca hubiéramos ido a por él si se hubiera ido a otra ciudad. Pero volver a la ciudad en la que había cometido su asesinato era para nosotros intolerable. :Ay!, pensé yo al leer tan sensatos argumentos: la justicia tendría que haberle advertido al asesino, tendría que habérselo incluido en la sentencia. Además de los años de cárcel, un asesino ha de perder siempre su condición de ciudadano (acaso sólo le quede ya la posibilidad de esa ciudadanía errante, vaga, abstracta, espectral que se llama «universal» o acaso la opción de iniciar una nueva ciudadanía en otro lugar). El pueblo aún lo sabe. ¿Que lección de sabiduría urbana nos dio el homicidio de esos asturianos!.

Más que a dar recetas para recuperar el pasado urbano vivo, el último punto de este discurso lo voy a dedicar a decir cuáles no son las soluciones.

- Uno de los mayores problemas de las ciudades contemporáneas es el de su esclavitud ante el tráfico de automóviles particula- res. La pérdida del pasado urbano vivo coincide con la conversión de las calles en carreteras, pero el arreglo del problema del tráfico no es tanto una cuestión de índole política (como el tema de la ciudadanía que aquí se ha tratado), sino de carácter fisiológico. No es fácil hablar de cultura urbana con las tripas revueltas, así que se ha cedido el problema a los cirujanos de tráfico o ingenieros de semáforos y circunvalaciones, creyendo que las cuestiones fisiológicas no tienen nada que ver con las cuestiones culturales o políticas. Pues bien, nada más falso, porque las calles rápidas con semáforos sincronizados o las autopistas de circunvalación son el signo más expresivo de la superposición de un estrato de movilidad sobre el viejo estrato físico de urbanidad, o del deseo antiurbano de los nuevos ciudadanos motorizados de huir lo más deprisa posible de la ciudad.

- Las ciudades actuales sin ciudadanos propios y con sus calles convertidas en carreteras han aceptado su condición de objetos inertes y en un último esfuerzo de superación se han puesto a la tarea de ser los objetos más caros, más antiguos, o más de moda. Han confiado su éxito o su salvación (su destino) en los museos y en los arquitectos de renombre y andan locas buscando cómo venderse en el nuevo mercado de ciudades-objeto que ha creado la imponente industria del turismo-cultura.

De hecho, el título del simposium que motivó la conferencia recogida luego en este escrito, era Nápoles-Barcelona, y proponía algo así como que los arquitectos de 
Barcelona, que tanto lustre y fama le habían dado a su ciudad (premiada desde Londres nada más y nada menos que con premio de arquitectura) contasen en Nápoles - una ciudad dejada de la mano de Dios- los secretos de su fórmula.

Ni que decir tiene que yo propuse allí que redescubriesen su ciudad desde su condición de napolitanos (como se le dice a un marido escéptico que redescubra a su extraordinaria mujer antes de hacer la tontería de escaparse con una pelandusca) y que no hicieran nunca lo que los políticos y publicistas de Barcelona dicen que han hecho con su ciudad: «ponerla guapa» para (eso ya no lo dicen) venderla a la industria del turismo, -cultura donde, efectivamente, ha obtenido el primer premio. Porque quien pone guapa a su mujer para venderla no hace otra cosa que prostituirla, y a la gente que hace ese tipo de cosas se le da un nombre muy feo como para decirlo aquí.

- Con todo, lo que peor le puede sentar a una ciudad, para volver a tener la vida que un día tuvo, es ser famosa. Le ocurrirá lo que a aquellos hombres que, según Jünger, se han hecho célebres: perderán su condición de buena vecindad.

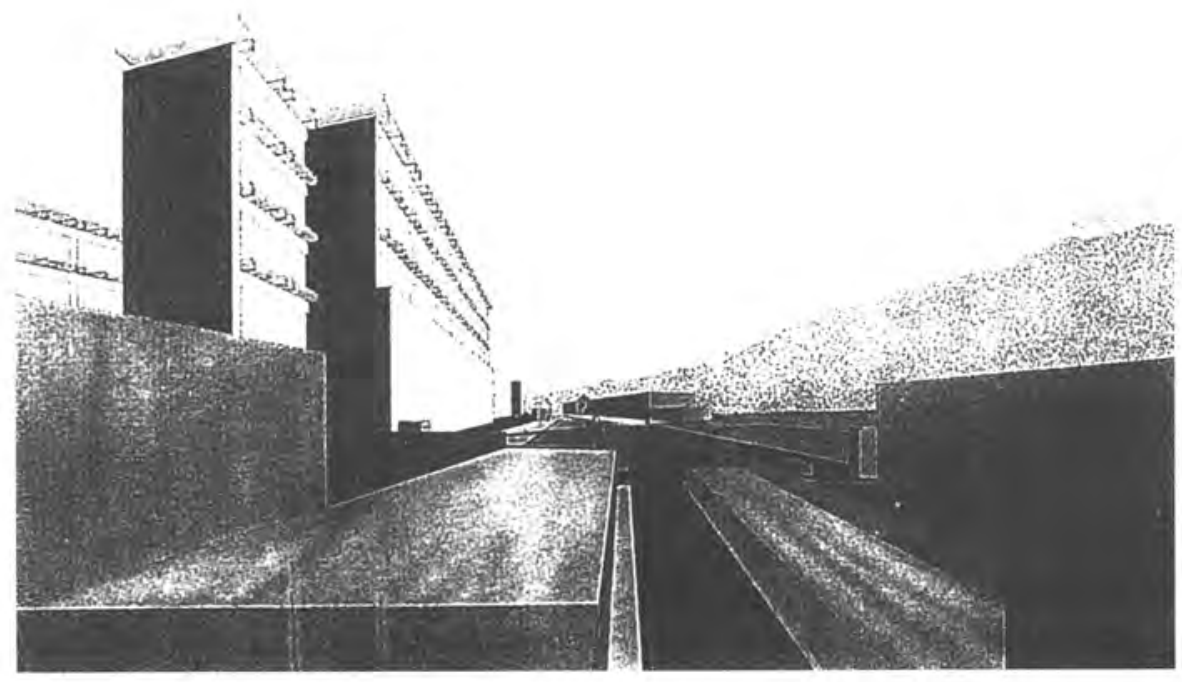

Área metropolitana de Karlsruhe. Estudios para el Albtal, cerca de Ettlingen. M. Meili, M. Peter, 1990 


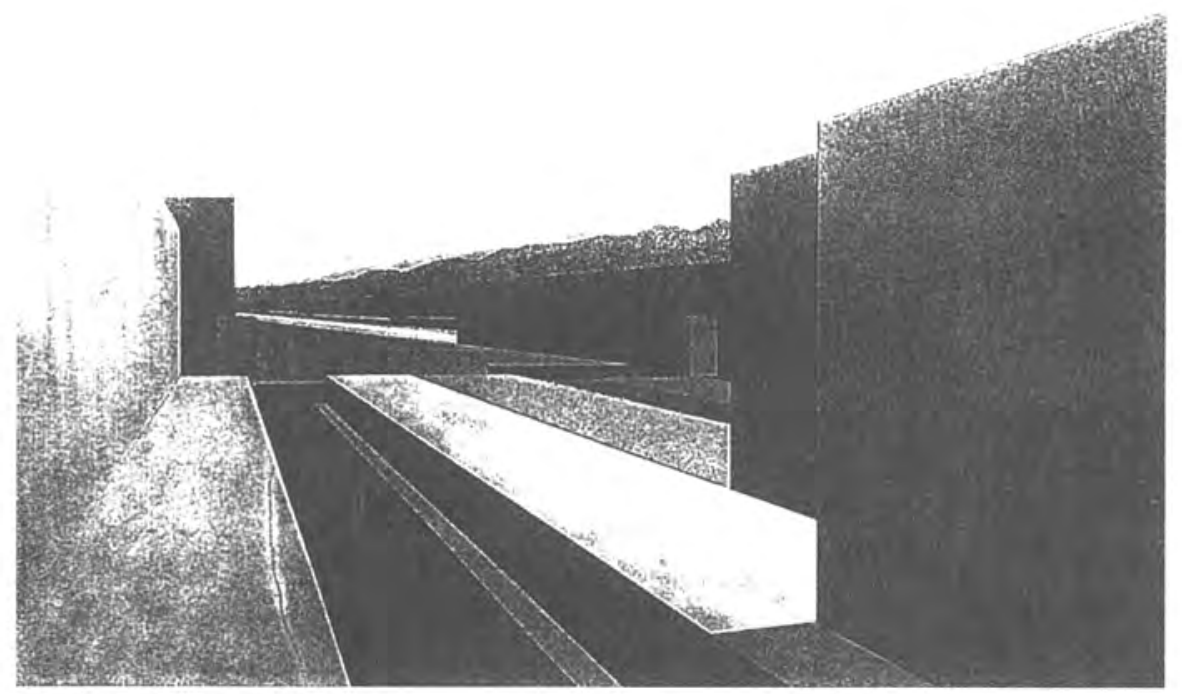

Estudios para el Albtal cerca de Ettlingen. M. Meili, M. Peter, 1990. 